\title{
LAS CIUDADES INTERMEDIAS COMO OBJETO DE ESTUDIO EN EL MARCO DEL CAPITALISMO PERIFÉRICO: EL MÉTODO COMO CONSTRUCCIÓN DE CONOCIMIENTO
}

\author{
INTERMEDIATE CITIES AS STUDY OBJECT UNDER THE FRAMEWORK OF PERIPHERAL CAPITALISM: - THE \\ METHOD AS A CONSTRUCTION OF KNOWLEDGE
}

\author{
Omar Arrieta Chavarría \\ ${ }^{1}$ Universidad Nacional de Costa Rica (UNA), Heredia, Costa Rica \\ Correspondência para: Omar Arrieta Chavarría. (oarrietac@gmail.co) \\ doi: 10.12957/geouerj.2019.46185 \\ Recebido em: 29 out. 2019 | Aceito em: 15 nov. 2019
}

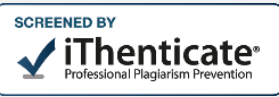

\section{RESUMEN}

En este artículo se parte de la idea del método como proceso de construcción de conocimiento en las investigaciones geográficas del espacio urbano de ciudades intermedias ubicadas en la periferia de la periferia del capitalismo global. En el análisis se recurre a algunos de los aportes de tres perspectivas teórico-metodológicas convergentes dentro del pensamiento crítico que, a mi juicio, son esenciales para desarrollar la pesquisa sobre el espacio geográfico en general y sobre las formas espaciales que asume la singularidad de las pequeñas ciudades en la periferia de los ejes de acumulación de capital, lo que nos conduce a analizar las desigualdades y la fragmentación socioespacial del territorio, las transformaciones en la morfología urbana y los cambios culturales que genera la globalización del mercado capitalista en sus manifestaciones más específicas a escala local, que constituyen el objeto de estudio de este trabajo. Esos tres enfoques son: primero, las teorías que trabajan la complejidad desde una perspectiva crítica; segundo, la epistemología crítica del configuracionismo latinoamericano; y tercero, el enfoque neomarxista en los estudios urbanos. El estudio desarrolla, de forma sucinta, algunos conceptos e indicadores que en la «reconstrucción de la teoría» se investigaron a nivel empírico en la ciudad de Liberia en la provincia de Guanacaste, Costa Rica, Centroamérica.

Palavras-chave: Ciudades intermedias. Periferia. Complejidad. Configuracionismo. Centroamérica.

\begin{abstract}
This article starts from the idea of the method as a processing of construting of knoeledge in the geographical research of the urban space in intermediate cities located on the periphery of the periphery of global capitalism. The analysis uses some of the contributions of three convergent theoretical-methodological perspectives within critical thinking that, in my view, are essential to develop the research on geographical space in general and about the spatial forms assumed by the uniqueness of small towns on the periphery of the capital accumulation axes, which leads us to analyze the inequalities and socio-spatial fragmentation of the territory, the transformations in urban morphology and the cultural changes generated by the globalization of the capitalist market in its most specific manifestations at the local level which constitute the object of study of this essay. Those three approaches are: first, theories that work on complexity from a critical perspective; second, the critical epistemology of Latin American configurationism; and third, the neo-Marxist approach to urban studies. The study succinctly develops some concepts and indicators that in the "reconstruction of theory" were empirically investigated in the city of Liberia in the province of Guanacaste, Costa Rica, Central America.
\end{abstract}

Keywords: Intermediate Cities. Periphery. Complexity. Configurationism. Central América

\section{INTRODUCCIÓN}


Un sector del pensamiento crítico latinoamericano actual ha enriquecido los estudios y el debate epistemo -metodológico sobre el proceso de investigación en las ciencias sociales abundando en la comprensión del método como construcción de conocimiento. Este artículo es una pequeña contribución dentro de la misma orientación epistémica para el estudio del espacio geográfico; particularmente, pensando en aportar al juicio crítico de las investigaciones en geografía urbana.

El propósito del escrito es mostrar por medio de algunas herramientas teórico metodológicas y conceptuales utilizadas en una investigación realizada en la ciudad de Liberia, en la provincia de Guanacaste, Costa Rica, de qué forma los geógrafos pueden generar nuevos conocimientos desde este enfoque crítico.

El reto nuestro fue implementar la teoría al estudio de caso, porque en geografía el "caso" (como espacio, territorio, paisaje o lugar) debe en distintos momentos afrontarse como concreto real, como abstracción y como concreto del pensamiento. Con la particularidad de que el espacio es una construcción sociocultural que no existe sin modificar el mundo físico natural, es decir del mundo de la naturaleza forma parte de la construcción del objeto. De tal manera que, para los enfoques críticos en geografía, es muy claro que el objeto es también sujeto activo. Como producto socio cultural, el espacio es además tecnología en movimiento que implica desarrollar habilidades del pensamiento dialéctico complejo, una especie de construcción dialógica entre naturaleza, sociedad y tecnologías como elementos de la cultura humana. Construcción teórico metodológica que no siempre se han hecho para las investigaciones empíricas del espacio urbano en Centroamérica.

El ensayo no procura demostrar la verdad de ninguna teoría, ni busca plantear hipótesis de trabajo, ni pretende llegar a conclusión alguna. Lo esencial aquí es el proceso de reflexión y señalar algunas de las articulaciones teóricas que surgieron en el proceso de una investigación sobre una pequeña ciudad centroamericana.

El artículo empieza resumiendo los aportes de pensamiento crítico marxista en relación con las teorías de la complejidad, pero, específicamente, con el configuracionismo latinoamericano, luego se destacan 
algunos aportes de la teoría critica para comprender Centroamérica con perspectiva geográfica y termina con un análisis empírico del espacio urbano de la ciudad de Liberia.

El ejercicio que ofrecemos al lector es que simplemente interprete desde su perspectiva la relación entre una "cartografía" que más que un resultado es un pretexto para la mirada crítica del vínculo histórico entre el método como construcción de conocimiento y las categorías o conceptos que ordenaron el proceso de investigación; en este caso, vínculo también mediado por las figuras, los mapas mentales y la cartografía temática que se presenta.

\section{Apunte sobre el método desde el pensamiento crítico en ciencias sociales}

Desde la complejidad se construyen teorías que (releen» el mundo de la naturaleza y la sociedad procurando un lenguaje común y la construcción de metodologías de análisis compartidas que postulan la necesidad de organizar el conocimiento científico transdisciplinario. La visión sistémica, unida a los nuevos principios científicos que explican la emergencia de estructuras nuevas o más complejas a partir de lo imprevisible, permite relativamente explicar aquellos sistemas dinámicos que ocurren en el mundo real natural o social. ${ }^{2}$ Desde el enfoque de la complejidad se propone una nueva forma de ver la relación sujeto-objeto. Las nuevas ciencias se caracterizan por el reconocimiento del objeto como sujeto cognitivo.

Por otro lado, en cuanto a la recuperación de las categorías clásicas del método de la economía política, De la Garza $(2001,2011)$ señala que en Marx hay un planteamiento metodológico cercano al constructivismo teórico y una noción implícita de estructura que no se parece a un sistema hipotético deductivo. Para este autor el método en Marx parte de unos fundamentos generales que son: el principio del método como reconstrucción de conocimiento, la idea de totalidad marxista, la inclusión del sujeto en

\footnotetext{
${ }^{1}$ Ver Lois, C. (2015) y su metamorfosis del concepto de "cartografía" por el de "fotografía" de Phillipe Dubois. Ver también Peláez, J. E. (2015).

${ }^{2}$ Y como señalaba Reynoso (2007), en las genuinas teorías contemporáneas de la complejidad y el caos hay algunas elaboraciones de carácter formal que podrían ser instrumentales en una investigación empírica, y entre ellas y en materia de complejidad siempre será necesario y posible ir más lejos o buscar en otro lado.
} 
la epistemología crítica, la mediación del dato empírico en el proceso de investigación por la teoría y por la relación sujeto-objeto investigado, y, por último, el concepto de configuración.

La teoría de la descripción articulada de la epistemología crítica de Zemelman (1990 y 2011a,2011b) nace de la definición del tiempo presente en la investigación social, presente que implica potencialidad de lo dado y que no es susceptible de anticipación teórica, ya que el futuro no está predeterminado. De ahí que este pensador propone abordar el problema a través de la desarticulación de conceptos, seguir hacia la descripción desarticulada y posteriormente hacia otra articulada que sería la nueva teoría (Andrade, 2007; De la Garza, 2001 y 2011; Pineda, 2011; Zemelman, 2011a y 2011b).

Zemelman otorga particular importancia al problema de la construcción del sujeto social. ${ }^{3}$ El concepto de configuración permite escapar del determinismo, del objetivismo y del estructuralismo sin caer en lo aleatorio o en el subjetivismo, y posibilita ver una parte de la realidad como ámbito de creación de sentido.

La totalidad como guía de la reconstrucción del objeto en el pensamiento puede adoptar varias formas dependiendo del objeto. Marx pone al método en función de la materia investigada (el objeto), del desarrollo de la ciencia (teorías y técnicas acumuladas) y de las transformaciones del propio objeto; el concreto-abstracto-concreto bajo una forma de razonamiento científico diferente del hipotético deductivo y de la hermenéutica en cuanto al uso reconstructivo y no deductivo de la teoría acumulada. Con una perspectiva abierta al descubrimiento frente a una realidad en transformación que no se subsume en ningún modelo, que obliga a la reconstrucción permanente, aunque haya aspectos de la realidad de pertinencia mayor que el caso específico, pero que al ser ubicados en una nueva articulación adquieren otro significado (De la Garza, 2011). En fin, De la Garza, allí mismo, resume las claves de esta propuesta teórico-metodológica, destacando primero la tesis de que el marxismo es esencialmente una metodología

\footnotetext{
${ }^{3}$ En Zemelman hay un interés por recuperar la historicidad en el plano del sujeto, ya que sin el movimiento del sujeto no se puede pensar la historicidad de las externalidades, pues habría una disociación entre sujeto y contexto. Con la epistemología crítica de Zemelman (2011a,2011b) se busca desarrollar el método como forma de potenciación de la realidad, así como reconocer que el conocimiento sociohistórico supone ser construido desde los espacios de intervención del hombre que se recupera en el planteamiento mediante el análisis de coyuntura como metodología que incorpora al sujeto, y concibe la realidad externa como espacio de construcción.
} 
de reconstrucción de la realidad, la recuperación que se hace desde el configuracionismo del sujeto y de la cultura (del sujeto -objeto), subrayando que el método de la economía política es un método de construcción de teoría y no de simple verificación de hipótesis, con dos momentos del proceso: el método de investigación y el método de exposición y que en la fase de investigación se elaboran conceptos a partir de intuiciones y representaciones, no como leyes universales, sino históricamente determinados; abstracciones que existen en lo particular concreto, y, finalmente, que el paso de lo simple a lo complejo pone en juego a la lógica, los conceptos, lo histórico, la génesis histórica y lo empírico, pero en la reconstrucción de la teoría como reconstrucción de la totalidad que adopta diversas formas dependiendo del objeto de estudio.

Estas ideas propias del configuracionismo latinoamericano, desde nuestra perspectiva, también constituyen un reto epistemo -metodológico para los estudios del espacio geográfico, puesto que la geografía históricamente ha tenido una gran vocación transdisciplinaria que se reflejan en el interés en el recorrido de esta ciencia, por integrar formas de comprensión del ecúmene (Estrabón), como totalidad compleja y contradictoria, muchas veces descrita como la "síntesis geográfica" pero que desde el pensamiento crítico, va más allá de las relaciones puramente socio-culturales, o de la relación sociedad - naturaleza, de las aprehensiones parciales de las llamadas "tradiciones geográficas". Es lo concreto real como totalidad espacial contradictoria, que se construye, si se quiere, "hologramáticamente" como objeto de conocimiento de la geografía.

El pensamiento marxista estudia los problemas del espacio geográfico en las sociedades actuales construyendo una teoría general para entender las formas de acumulación del modelo neoliberal dominante. Desde los primeros aportes de la geografía radical ${ }^{5}$ aparece el interés constante por explicar el espacio como una categoría articulada a los procesos sociales, en tanto da cuenta de las contradicciones sociopolíticas y económicas de la economía de mercado y del papel que juega en ese proceso la apropiación estratégica de los territorios y sus recursos.

\footnotetext{
${ }^{4}$ Es decir, como acción perceptiva consciente que capta, interpreta y traduce la realidad produciéndose para reconstruirla reorganizando los datos del objeto espacio geográfico, objeto palabra, objeto material, imagen símbolo, texto, discurso.

${ }^{5}$ Por ejemplo, en toda la producción de los setenta de la revista Antipode, pero también en otras publicaciones de aquella época.
} 
El bagaje teórico-metodológico que existe sobre la ciudad y los espacios urbanos tiende a producirse mayoritariamente en los países capitalistas desarrollados, para objetos de investigación de aquellas latitudes. Y decir latitudes en los estudios espaciales puede ser un condicionante o una variable fundamental al realizar una investigación en este campo.

En la década de los noventa y durante el primer lustro de este siglo, los estudios se centraron en comprender del proceso de acumulación flexible, en cómo evoluciona el capitalismo tardío a partir de la crisis del setenta (Harvey, 1990, 1997, 2000 y 2004; Soja, 1989 y 2000) y en el análisis de la ciudad posmoderna; por ejemplo, Harvey (1990, 2000 y 2004) y Soja (1989 y 2000) dedican gran parte de sus escritos a estudiar el espacio urbano desde una crítica a la economía política y desde una teoría inspirada en el pensamiento francés, particularmente en la obra de Henry Lefebvre y sus investigaciones pioneros sobre el espacio urbano.

Estos escritos se acercan, en algunos casos, a las reflexiones posmodernas de la ciudad con un fuerte contenido de la lectura de lo urbano como construcción de una cultura global extremadamente contradictoria. Se discurre sobre los pequeños relatos de los espacios fragmentados, sobre las formas de acumulación flexible que incorpora fragmentos de las ciudades del Tercer Mundo.

El espacio urbano es producto de la división social y territorial del trabajo, escenario de relaciones sociopolíticas conflictivas por las contradicciones de clase y la apropiación desigual del territorio, y es el producto material y cultural que resulta de las posibilidades, las necesidades y los intereses antagónicos de los distintos agentes sociales que viven dentro o fuera de la ciudad. 


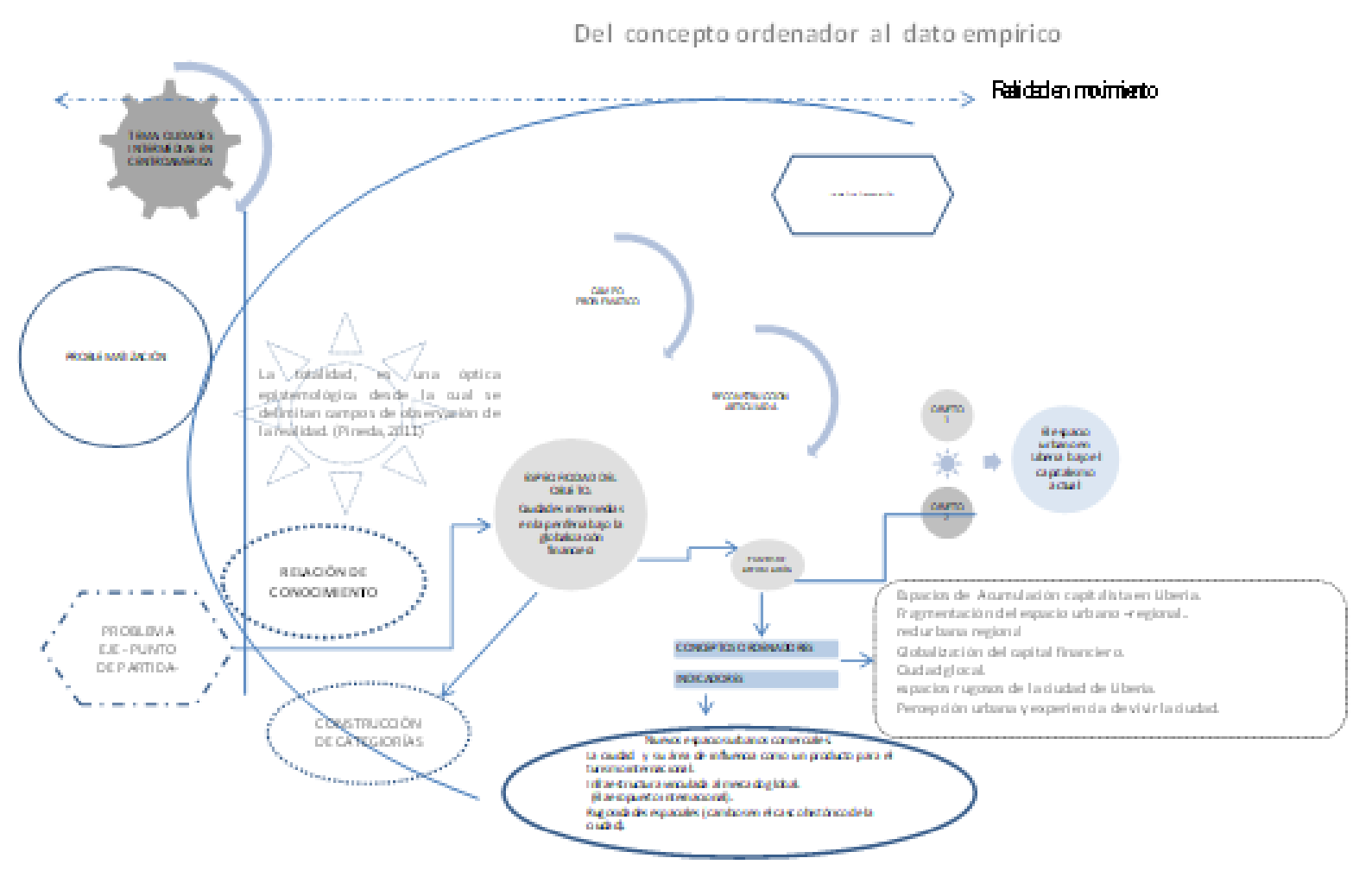

Figura 1. Esquema metodológico de La configuración del espacio urbano en Liberia

La urbe como construcción sociocultural histórica es una totalidad sensible a cualquier proceso político, cultural o económico, y en tiempos de crisis o de bonanza se transforma en función de tales ciclos. Aparecen, por ejemplo, los suburbios o las áreas periféricas como nuevas manifestaciones de la acumulación (Harvey, 2006a).

Así, el marco teórico-metodológico de los estudios urbanos hoy está compuesto de categorías de análisis que describen procesos muy concretos: desigualdad espacial, fragmentación socioespacial de la ciudad, acumulación por despojo (Harvey, 2006b, 2009b, 2010a y 2010b) en territorios o lugares específicos y en tiempo presente, el spatial fix, el toxic capitalism, lo multiescalar (Jessop, 2006; Harvey, 2006b; Smith, 2009), y la democratización y del derecho a una ciudad que promueva la emancipación.

Todos estos procesos reflejan lo polisémico de la lectura del espacio bajo el capitalismo global. Pero nunca se puede perder de vista que el espacio-tiempo de los acontecimientos humanos tiene, inevitablemente, un componente de arraigo. No se puede estudiar el espacio urbano (como un producto social) sin hacer referencia a espacios complejos pero concretos, históricamente determinados. 
De qué manera los procesos antes descritos ocurren en zonas de la periferia, en un subcontinente que presenta una configuración del espacio particular, es parte de la reflexión de partida en esta propuesta de interpretación de las ciudades pequeñas y los espacios o redes urbanas a ellas asociados. Es decir, en nuestro caso, reconstruir una teoría articulada para el análisis y la comprensión de las ciudades centroamericanas tal y como se resume en la figura 1.

\section{Sobre el dato empírico desde la epistemología crítica.}

El método como construcción de conocimiento resignifica el dato empírico que no es "homogeneizable en todas las disciplinas y por tanto sujeto a nuevas mediaciones» y tampoco "puede haber una base empírica universal independiente de las teorías»(De la Garza, 2001, p. 6). “El dato depende siempre de los conceptos utilizados, pero también de las interacciones entre investigador e investigado y de los sentidos que el primero suscita en el segundo ${ }^{6}$ (De la Garza, 2011, p. 13).

El dato se construye en función del objeto a través de una perspectiva. Y es resultado de la reconstrucción que viene del concepto ordenador ${ }^{7}$ al indicador y luego al dato, es decir, el dato depende en parte del concepto. Por otro lado, el dato de expresión de sujetos es doblemente construido e interpretado, por quien investiga y por quien proporciona la información. El encuentro en el diálogo interrogativo supone del lado de quien responde una interpretación del sentido de la pregunta y una construcción de la respuesta. En esta medida el dato es triplemente construido, desde la teoría y desde la subjetividad de los interrogados y del interrogador, es más complejo que simples imaginarios y simples significados subjetivos. El dato, como la misma realidad, tiene componentes subjetivos y objetivos, ambos son reales,

\footnotetext{
${ }^{6}$ Las cosas no son solo objeto de contemplación, sino también praxis. Y en cuanto al dato empírico, es imposible que haya dato en estado puro y solo para verificar. En el concepto de experiencia (y el de praxis) hay una relación compleja en donde las concepciones del sujeto sobre el objeto son parte de la misma realidad y no un reflejo (para ampliar véase De la Garza, 2011).

${ }^{7}$ Los conceptos ordenadores tienen una función de búsqueda de relaciones posibles, para lo cual deben desarticularse de los corpus teóricos de los cuales provienen. Esta búsqueda de relaciones posibles pretende una primera aproximación al universo empírico del área y nivel respectivo. La articulación de los conceptos ordenadores básicos radica en la posibilidad de traducirlos en indicadores "empíricos» cuya función no es la "verificación» del propio concepto, sino "la reafirmación o el descubrimiento de nuevas relaciones entre los conceptos. Se trata de operacionalizar para aproximarse y reconstruir la realidad y no para verificar una realidad dada (Zemelman, 1987, citado por Escolar, 1998).
} 
son una realidad siempre mediada. En un método de construcción de teoría el dato empírico no verifica los conceptos, ayuda a reconstruirlos (De la Garza, 2011).

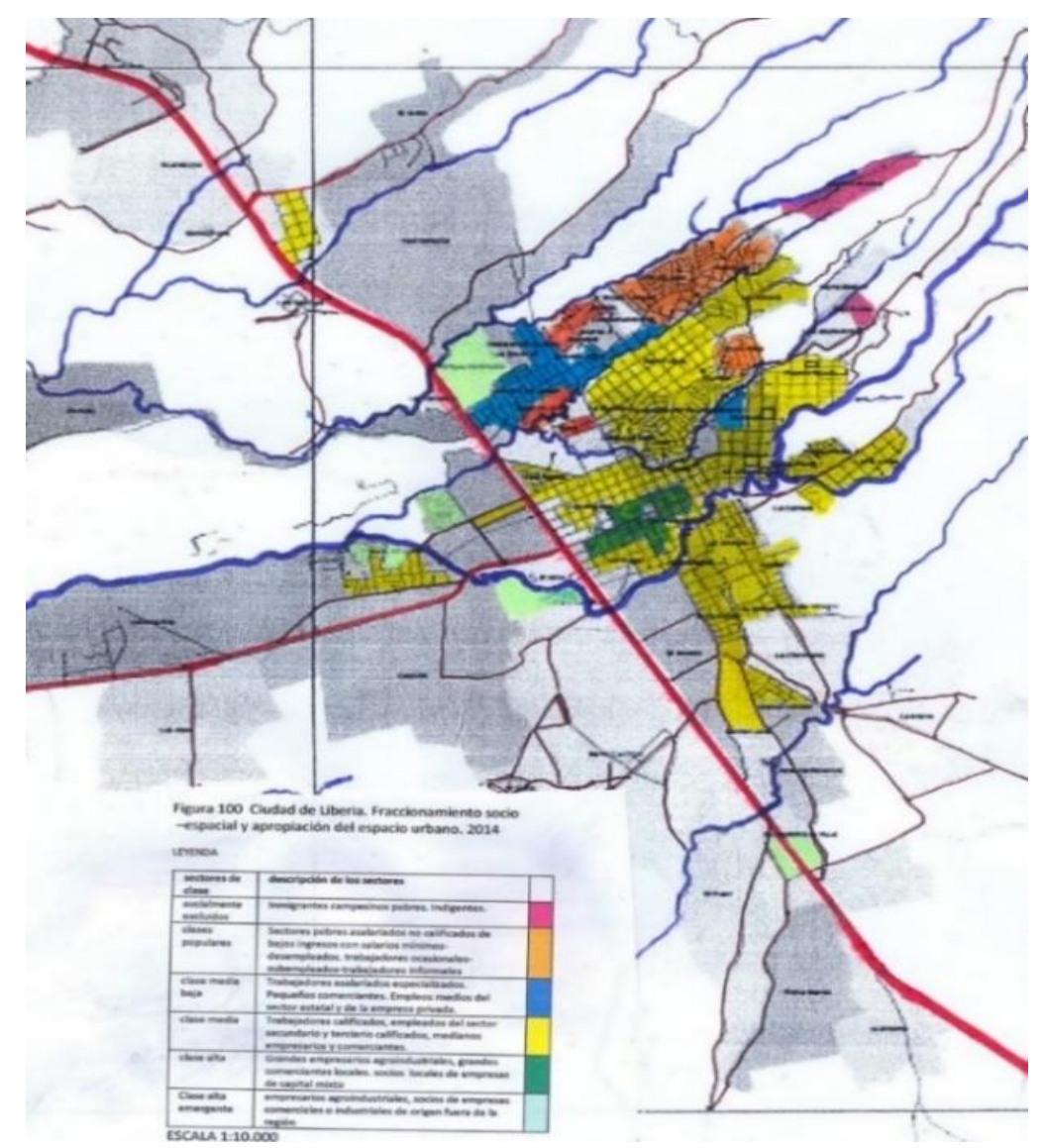

Figura 2. Fragmentación social de la ciudad según la percepción de las personas. Las categorías empíricas se construyeron con fines operativos, a partir del trabajo de campo realizado previamente, para motivar la discusión en los talleres.

Escolar (1998) resume el papel del dato en la construcción de conocimiento, señalando que adquiere sentido solo en función del problema de investigación y que la definición de su significado concreto pasa por la determinación del contexto de su construcción en la realidad. Y agrega que durante el proceso de investigación se produce una triple tensión: de la teoría que pide determinados datos; de la subjetividad del investigador; y de la realidad que existe independientemente del proceso de investigación.

Esta autora nos recuerda, a propósito del trabajo de campo en geografía, que a "la realidad concreta" se le interroga desde alguna perspectiva teórica — también seleccionada deliberada y racionalmente-. Es así que las relaciones que se establecen en el trabajo de campo responden a una construcción de lo real por parte del investigador, a una selección de una parte de "la realidad" luego de una selección de una 
parte de la teoría y de los conceptos ordenadores que conforman el modelo teórico que sirve como orientador. Para Escolar (1988) lo real resulta un recorte epistemológico del investigador, que descansa y remite a una socialización cognoscitiva del objeto, y el dato forma parte únicamente de nuestra manera particular de aprehensión de la realidad que estudiamos, de nuestro propio recorte de lo real, es, entonces, un recurso metodológico de la investigación para la comprensión de lo concreto real, sin que este se conozca totalmente ni se resuelva. Se trata tan solo de una nueva interpretación de lo concreto real.

La relación entre el sujeto y lo real en tanto que recorte lo crea y lo ordena, y a la vez en sí misma, esta relación es tan solo un nuevo discurso sobre lo real. Lo real informa a la teoría y la teoría permite percibirlo, formularlo y dar nueva cuenta de él (Escolar, 1988). Así éste participa del proceso de construcción de conocimientos a través del proceso de su propia construcción mediante los conceptos ordenadores que configuran la descripción articulada (siguiendo a Zemelmann)

Esta es, en fin, la dialéctica entre lo real y la teoría, para dar cuenta de alguna manera de lo real transformado en el proceso de investigación en general y también en las investigaciones sobre el espacio geográfico y sus expresiones particulares.

\section{La ciudad en Centroamérica como objeto de estudio ${ }^{8}$}

Con el concepto de ciudad intermedia se hace referencia a lo que en la geografía tradicional descriptiva se llamaban ciudades medianas o secundarias destacando la función que realizan estos poblados en el territorio y

${ }^{8}$ Algunas ideas aquí expuestas aparecen preliminarmente desarrolladas en Arrieta, 2012 y 2014. 


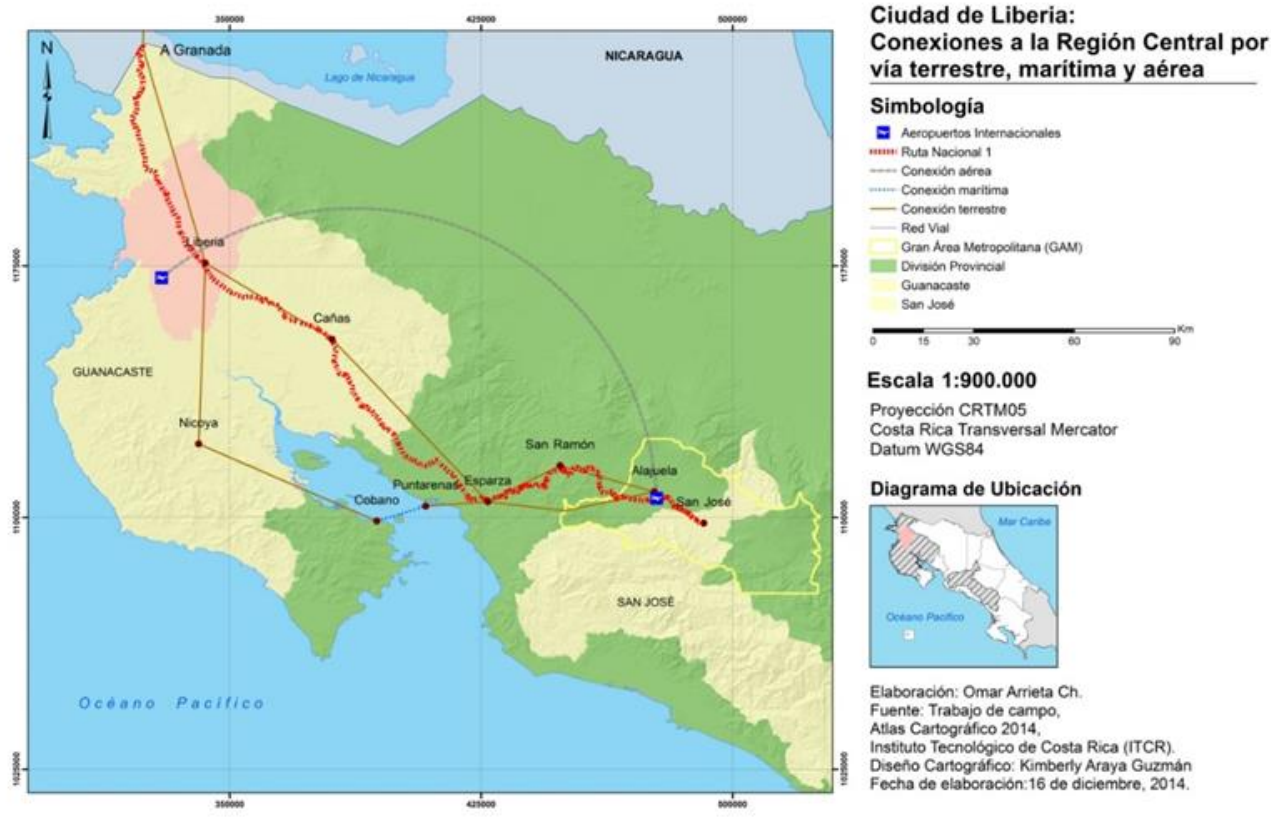

Figura 3. Liberia ciudad intermedia de Costa Rica y Centroamérica.

su vocación de articular los espacios concretos con otros nodos y territorios más o menos lejanos; el concepto de núcleo o nodo urbano intermedio incluye, aspectos más dinámicos y estratégicos que incorporan nuevas posibilidades para la autoafirmación y el reforzamiento de la ciudad-región y su apertura y consolidación a diferentes escalas.

Cuando se dice que el objeto de conocimiento es la ciudad intermedia se hace referencia al rol espacial que juegan en el proceso de globalización y de crisis actual del capitalismo; ${ }^{9}$ segundo, los cambios que sufre el espacio en estas ciudades; tercero, el impacto de estas transformaciones sobre el área de influencia de la ciudad; y cuarto, como punto de partida y de llegada, las formas particulares que vinculan a la urbe intermedia con los procesos globales de acumulación de capital.

Estos pequeños y medianos núcleos poblacionales situados fuera de las aglomeraciones metropolitanas primadas se destacan por su papel de intermediación del capital trasnacional, independientemente del

\footnotetext{
${ }^{9}$ La globalización es la expresión superior de la transnacionalización del capital, con predominio absoluto de un capital financiero especulativo, este proceso desvinculó al capital de su relación directa con las actividades productivas que posibilitaban un mayor autocontrol de las crisis internas del sistema. Comienzan a operar mecanismos artificiales de reproducción del capital... el capital comienza a disociarse del territorio, de la actividad productiva y genera su propio mundo virtual, su propio mundo de reproducción, que no es congruente con lo que está pasando en la actividad productiva hoy (ver Zemelman, 2011b, p. 14).
} 
tamaño y de la complejidad de las funciones urbanas que cumplan en su área de influencia. En otras palabras, un "nodo urbano" intermedio está, de alguna manera, directamente ligado al capitalismo global, no es pues lisa y llanamente una ciudad secundaria. Pueden ser pequeños espacios de países pequeños que se encuentran directamente conectados con los circuitos del trasiego de mercancías, incluyendo las personas, y eventualmente cumplen funciones diversas vinculadas a actividades como los servicios y el comercio ligado a la demanda internacional, por ejemplo, del turismo y de los recursos naturales y materias primas locales.

\section{La especificidad del espacio en ciudades intermedias.}

Una cuestión sustantiva para el estudio del espacio geográfico en general y del espacio urbano en particular es comprender la condición histórica concreta de cada ciudad, y por qué se habla de leyes de tendencia que explican su comportamiento, a sabiendas de que no es posible hacer generalizaciones válidas sobre el crecimiento y desarrollo de todas las ciudades intermedias. En este trabajo lo que se intenta es desarrollar categorías de análisis, conceptos y una metodología que construye nueva teoría para una ciudad en particular, que eventualmente podría servir de referente en la acumulación de teoría en este campo. El estudio podría ayudarnos a comprender, a explicar o no, o parcialmente, lo que ocurre en otras ciudades de Centroamérica. Es decir, construimos conocimiento sobre un sujeto- objeto particular, históricamente irrepetible, pero las herramientas estructuras objetivas de pensamiento se abren de igual forma con el método para elaborar nuevas teorías sobre objetos de estudio similares que, como cosas singulares de existencia, se ponen al descubierto en la reconstrucción permanente de la ciudad que existe. Esto, en el campo de la geografía es esencial, porque el anclaje urbano ocurrirá siempre en un espacio históricamente determinado.

Recurriendo al estudio de caso se procura, en principio, identificar algunas de las categorías de análisis asociadas a la explicación cualitativa de las ciudades "de segundo o tercer rango" en el Istmo y explorar las invariantes que ayuden a comprender mejor la totalidad singular que las define y las "encierra"10.

\footnotetext{
${ }^{10}$ Toda totalidad es una singularidad, por ejemplo, nuestro planeta es una totalidad desde nuestra experiencia, pero es una singularidad en el universo. En el Método de la Economía Política, la totalidad delimita, encierra, recorta para reconstruir y comprender, es decir, la comprensión es explicación articulada por niveles de pertinencia, por la legalidad teórica del objeto en construcción, de lo concreto real pensado.
} 
El emplazamiento (el sitio) de un nodo urbano intermedio puede convertirse en un elemento mediador clave para la comprensión histórica de sus funciones dentro de su región y del rol que desempeña a diferentes escalas espaciales junto a otros puntos de la red en el contexto nacional e internacional; por esa razón estos centros urbanos reflejan situaciones regionales o locales muy diversas (Bolay y Rabinovich, 2004; Cuervo, 2003; Gómez, 2005; Pulido, 2006a). Un ejemplo de ello se muestra en Figura 4 si se lee prudentemente el patrón de la red urbano regional del cantón de Liberia.

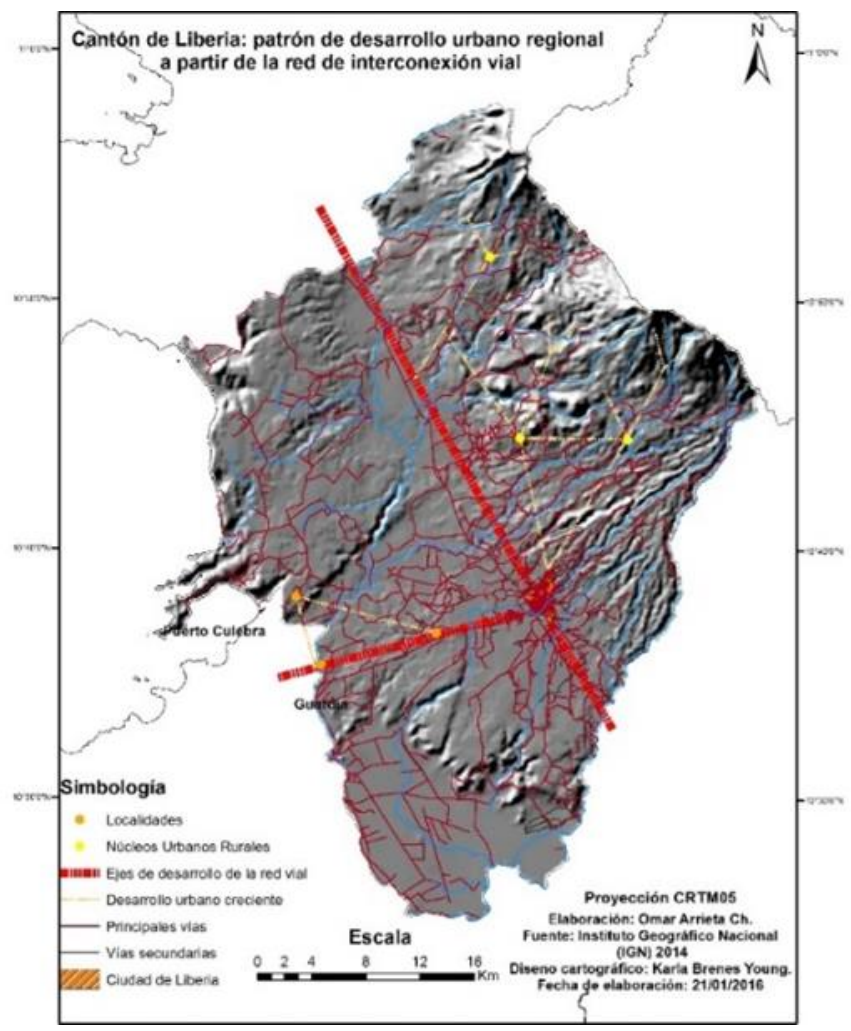

Figura 4. Liberia Importancia estratégica del sitio y situación en la red del crecimiento urbano regional.

De igual modo, la ciudad incorpora los espacios de su entorno inmediato, su periferia ${ }^{11}$ como "extensión” del proceso globalizador que, entre otras cosas, dispersa y fragmenta los asentamientos urbanos y difumina sus alrededores. Situación que grosso modo se repite en la pequeñas y medianas áreas

\footnotetext{
${ }^{11}$ Se trata de "un complejo territorial que expresa una situación de interfase entre dos tipos geográficos aparentemente bien diferenciados: el campo y la ciudad. De difícil definición conceptual y delimitación, cuenta con la desventaja de que es, en cuanto a objeto de investigación, un territorio "resbaladizo", en situación transicional, en permanente transformación (o con expectativas de ser transformado), frágil, susceptible de nuevas intervenciones. Con el paso del tiempo, el periurbano "se extiende", "se relocaliza", "se corre de lugar" (...) Se trata de un territorio en consolidación, bastante inestable en cuanto a la constitución de redes sociales, de una gran heterogeneidad en los usos del suelo. Ha recibido diversas denominaciones: la periferia urbana, el rururbano, la "ciudad difusa", la frontera campo-ciudad, la "ciudad dispersa", territorios de borde, borde urbano/periurbano, el contorno de la ciudad, extrarradio, exurbia, etc. Es un espacio que se define por la indefinición: no es campo, ni es ciudad» (Barsky, 2005, p. 1).
} 
urbanas.Para muchos estudiosos de los núcleos urbanos y de la cuestión urbano-regional, el desarrollo de un nodo intermedio depende del cometido que tiene asignado por su localización geográfica; de las características de su estructura productiva interna y de su entorno inmediato; del vínculo con su área de influencia; del grado de autonomía en la administración local; del marco institucional desde el cual ejerce el poder, de las formas de ese dominio y de las relaciones de mercado que establece con el exterior, que serán siempre de mediación entre las metrópolis regionales y los nodos urbanos de alcance continental o mundial, es decir, de los sistemas de ciudades. Es por esa última razón que reflejan, en algunos casos, la dificultad que tiene la metrópoli central de la cual forman parte para satisfacer muchas de las necesidades que surgen con las nuevas formas de penetración del capital. De esta manera, pequeñas o medianas poblaciones asumen nuevos roles para atraer dineros que buscan lugares más propicios y rentables. Son espacios para la revalorización del capital. Estos núcleos han sido útiles para salir de las crisis financieras como la actual (mediante las inversiones especulativas) o para evidenciar la fragilidad de las economías locales dependientes y subordinadas al mercado total.

En núcleos urbanos fuertes ${ }^{12}$, las relaciones más estrechas y más sólidas se producen primero entre las metrópolis globales, luego entre metrópolis con flujos aun no globalizados, que son nodos no dominantes en la red urbana mundial, y finalmente entre pequeñas metrópolis ubicadas en la periferia del capitalismo. De este modo los flujos de capital, de materia prima, de fuerza de trabajo, de información, de productos básicos estratégicos y de gestión de las empresas tienen esa condición multiescalar y en redes: es el postfordismo, la era de la acumulación flexible y su incursión en los nuevos espacios geográficos. Esto produce el carácter asimétrico, desigual, en el que se desarrolla las urbes dentro del neoliberalismo económico.

Este proceso, no solo se ocupa de desarrollar el mercado total, sino que trae consigo transformaciones en la cultura, en la geopolítica y en la relación entre sociedad, tecnología y naturaleza. Los cambios sociopolíticos, el desarrollo de las fuerzas productivas y la voracidad del mercado exigen cambios tecnológicos que transforman la naturaleza en general y los pequeños territorios dependientes, en particular.

${ }^{12}$ Las áreas metropolitanas del mundo 
En fin, la globalización ha impactado de forma diversa a las urbes que se encuentran fuera de las grandes áreas metropolitanas. Y depende mucho, del sitio y de su situación geográfica, la explicación del porqué unas y no otras ciudades pequeñas o medianas se vinculan con mayor o menor intensidad a las redes internacionales.

$\mathrm{Al}$ crearse a escala subregional pequeños nodos urbanos ligados al mercado planetario según el concepto propuesto por Dematteis, (1991 y 1998), ejercen nuevos roles en el ámbito nacional y en la esfera continental. Las funciones cambian y se redefinen de acuerdo con la dinámica regional subnacional, pero también según el papel que jueguen los nudos en los circuitos de las empresas globales. Es decir, se redefinen según las nuevas necesidades de ubicación del "dinero" o siguiendo los procesos de acumulación por desposesión.

\section{La configuración del espacio intermedio desigual.}

En general en Centroamérica a partir de la primera década de este siglo la crisis coyuntural del capitalismo, por ejemplo, la del 2007 y las que le han seguido debilitaron al sector de la construcción en algunas zonas bajo dominio del capital transnacional. Pero en otras áreas del Istmo, se han invertido grandes cantidades de dinero público y privado para transformar esos espacios. Sin embargo, lo común es que tanto en Baltimore ${ }^{13}$ (por citar un caso) como en los núcleos urbanos intermedios de nuestra región, el goteo llega hasta cierto límite y los pobres quedan siempre excluidos de toda posibilidad de acceder a la riqueza socialmente producida en el campo y en la ciudad. La figura 5 sobre diferenciación de los espacios emergentes muestra claramente este fenómeno en el cantón de Liberia.

Como producto de la acción de agentes inmobiliarios aparecen cambios en la morfología urbana, el desarrollo de grandes superficies comerciales, la modernización de la red de telecomunicaciones, la proliferación de edificaciones de mayor altura, el desarrollo de condominios cerrados, la expansión de las áreas con instalaciones comerciales y de servicios vinculados a la economía mundial y el incremento de viviendas para las clases medias, junto a la proliferación de extensas áreas de vivienda de interés social

${ }^{13}$ A propósito de los estudios de Harvey sobre esa ciudad 
en las periferias con condiciones ecológicas y paisajísticas aun no muy rentables para el capital. Todo esto agudiza las desigualdades socioespaciales y polariza y fragmenta el espacio de las pequeñas urbes centroamericanas.

En una ciudad intermedia del "Centro", el sector inmobiliario puede jugar un papel fundamental en la acumulación de capital dentro y fuera de ella. Esto se observó diáfanamente y por corto tiempo en la actividad de bienes raíces y construcción en los Estados Unidos de Norteamérica dinamizando la economía interna con la burbuja financiera. Lo mismo ocurrió en las regiones metropolitanas de Centroamérica, pero no con la misma fuerza y con el mismo rol protagónico de los países centrales. El capital inmobiliario al interior de los cascos urbanos no ha sido tan dinámico en esta área. En el Istmo lo que ha habido es un crecimiento lento del sector habitacional destinado a grupos de altos ingresos. El sector inmobiliario también tiende a dinamizar la red bajo la influencia de un nodo intermedio, pero no necesariamente como resultado del boom de la vivienda ${ }^{14}$, sino producto del desarrollo de la construcción que se dirige hacia los asentamientos rurales y las zonas costeras abarcando complejos hoteleros e inversiones similares, y en donde los recursos paisajísticos son más preciados e invertir en bienes raíces bajo formas de desposesión es altamente rentable. Se configura así, en el entorno urbano intermedio, una incipiente ciudad difusa. ${ }^{15}$

\footnotetext{
${ }^{14}$ Por ejemplo, la clase media en Centroamérica tiene dificultades para adquirir una residencia familiar. El ejemplo más claro es Costa Rica, con una amplia clase media que no ha podido resolver el acceso a la vivienda, ni siquiera en la Región Central en donde las capas medias son económicamente más fuertes y con mayores posibilidades de acceso a los créditos que en el resto del país, por las mejores y más estables condiciones de trabajo. Por otro lado, algunas ciudades costeras emergentes evidencian el crecimiento urbano suntuario, junto a los complejos hoteleros estimulados por el paisaje escénico y la presencia de capital internacional.

${ }^{15}$ Con el desarrollo de las redes tecnológicas la ciudad compacta se vuelve difusa. Es decir, con la globalización del mercado algunas actividades productivas tienden a deslocalizarse, el contorno de la ciudad se torna borroso, sus rasgos dejan de ser fácilmente reconocibles, lo plástico se estira, lo flexible se dobla más y más. La ciudad se convierte en objeto de especulación; de esta forma se retroalimenta el sistema creando una incipiente ciudad difusa en la región separando funcionalmente sus usos y segregando social y territorialmente a la población. Esta tendencia genera efectos negativos (dispersión de sistema y ocupación extensiva del territorio aledaño, en algunos casos reducción del espacio agrícola rururbano, fragmentación de la estructura comercial y de servicios, ruptura de los espacios cotidianos, incremento en las necesidades de movilización, subida del gasto energético y aumento en el consumo de agua y en los desperdicios). Al mismo tiempo, si el capital transnacional se apropia de la periferia, el Estado que se pone al servicio de esas empresas mejora allí las condiciones para que operen. Con ello se tiende a elevar, en "las afueras más rentables», la calidad de las redes de infraestructura, los servicios de transporte, telecomunicaciones y de conocimiento (ver fig. 4), y elevando de manera exorbitante los precios del suelo. Este es el juego que hoy se vive en las pequeñas ciudades tomadas por grandes inversionistas de la élite económica Centroamérica, y de fuera, con capitales de Europa y los Estados Unidos de Norteamérica.
} 


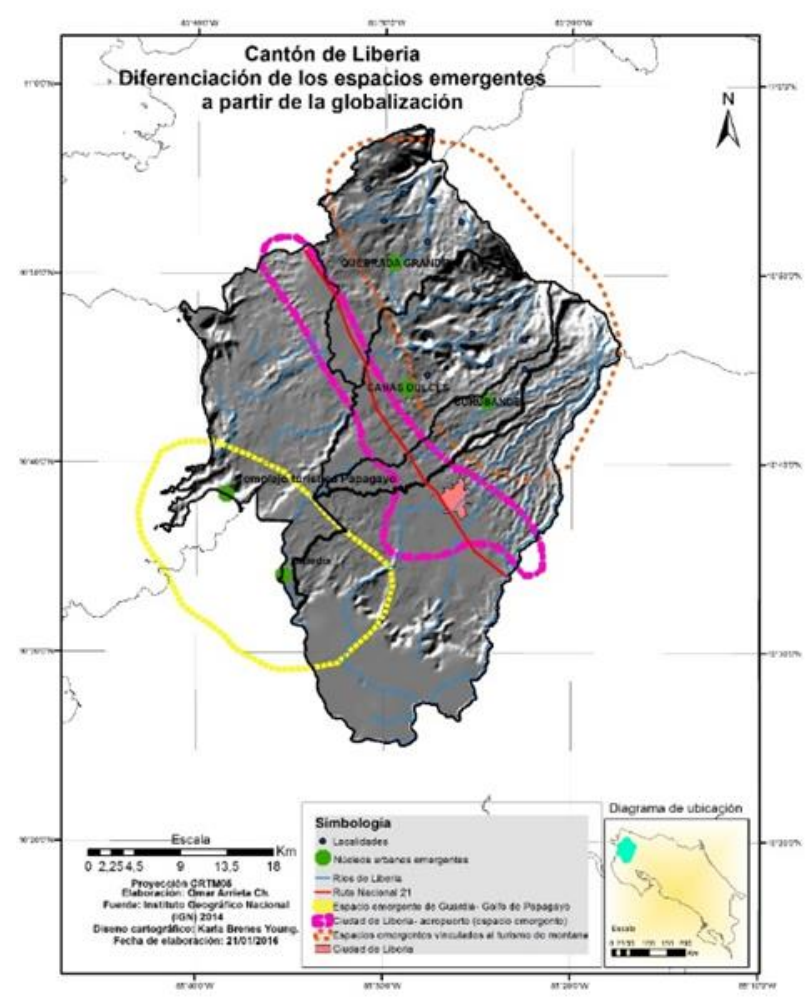

Figura 5. Liberia. Los espacios emergentes con la globalización dinamizan los paisajes del área de influencia urbana.

Las ciudades intermedias durante los últimos treinta años han logrado captar en gran medida las nuevas inversiones de capital. Además, en ellas tienden a expresarse con mayor agudeza las contradicciones y desigualdades en las condiciones de vida que genera el modelo de desarrollo económico actual, que se visualiza de manera espectacular en la transformación que sufre el paisaje periurbano y las áreas bajo influencia de esos núcleos urbanos.

\section{La cultura en la periferia de la periferia globalizada}

La crisis del capitalismo global hace que este se mueva hacia zonas que no habían sido convertidas anteriormente en "bienes de consumo" para el mercado total. Se asiste a un capitalismo multinacional (Jameson, 1991) cuya lógica es irrepresentable y cuya representación material ocurre en el caleidoscopio cultural de hoy, en el vértigo que produce la velocidad de las innovaciones tecnológicas que rompen y recomponen las identidades, los espacios, la sociedad, la cultura, la naturaleza. Se mezcla en el espacio, en el paisaje urbano y rural, lo nuevo y lo viejo, como espacios luminosos, opacos, rugosos, en términos de Milton Santos. 
En el paisaje y en la cultura de ciudades y regiones periféricas como Centroamérica quedan los desechos de una sociedad preindustrial mezclados con formas inacabadas de aquella fase capitalista de la revolución verde, junto a las nuevas exigencias de la demanda global del ocio.

La relevancia de variables como el transporte (por ejemplo, distancia de los aeropuertos a las costas), físico-naturales (el clima, la biogeografía y el paisaje natural), vocación urbanizable de los suelos o, la conexión directa a los centros dominantes que impulsan el "crecimiento económico», son factores geográficos que contribuyen a la instauración de una cultura posmoderna en estos territorios, que, como dice Jameson (1991), nos trae una sociedad más flexible, basada en la información on line y el mercado del sexo, el narcotráfico y el lavado de dinero que se agazapa en el culto a lo natural y a la naturaleza, a la cordialidad y al "buen vivir".

Se impone así el interés del capitalismo de adentro y de afuera por construir espacios para satisfacer prioritariamente las necesidades de los de afuera y para partir en dos el espacio de la ciudad: uno que mira hacia lo global y otro que se queda en lo muy local, en los barrios de la periferia marginal de la ciudad que también crece y adquiere su propio dinamismo (Borja y Castells, 2000).

El capitalismo de las grandes corporaciones internacionales tiene más libertad para penetrar la ciudad que se extiende y a la que impone su propia concepción del mundo, de los valores, de la belleza, del bien y del mal, de lo que debe ser perdurable, de lo que debe ser satanizado, de lo real-posible y lo imaginarioideal; y queda la imagen de la ciudad a través del mundo de los poderosos, con la visión del espacio urbano trazada por los grandes inversionistas, con su idea de lo público y lo privado, lo comunal y lo individual. Así, se juntan el espectáculo, la fiesta, la fastuosidad, la pobreza y la exclusión; así, el espacio, el mundo inteligible y las acciones humanas se fragmentan y languidece, además, la capacidad de autoorganización y la participación desde abajo. Las ciudades en general (y las intermedias no son la excepción), tienden a ser escenario de mayores y constantes transformaciones, de relaciones complejas entre sujetos diversos con subjetividades distintas, con intereses multivariados y con relaciones complejas y dispares entre cultura y poder. 


\section{El estudio de la ciudad de Liberia desde el método como construcción de conocimiento}

Con el pensamiento crítico configuracionista se ilumina un escenario de encuentros epistemológicos que enriquece la comprensión y el análisis de las características particulares de la totalidad sistémica compleja de los espacios (en plural), para el estudio de los procesos urbanos en general. En este caso, para proponer una lectura nueva del espacio urbano de la ciudad de Liberia. Para ello, antes se contextualizó territorialmente a Liberia formando parte de una totalidad mayor inmediata, con una historia y una geografía semejantes: la de las ciudades intermedias del Istmo. De ahí que el recorrido empírico metodológico tenga como punto de partida el presente histórico definido por la transnacionalización de la economía neoliberal, la crisis actual del capitalismo y su impacto en América Central, con la finalidad de exponer que tal recorrido recupera epistemo metodológicamente, el proceso singular de transformación y el papel que juega Liberia como espacio geográfico que no está separado de una estrategia mayor de participación del capital trasnacional en la región.

\section{Problematización del objeto de estudio.}

La problematización del objeto de estudio en este caso particular se inicia examinando las transformaciones que sufre Liberia en la coyuntura actual. Una pequeña ciudad de unos 63.000 habitantes ${ }^{16}$ ubicada en la provincia de Guanacaste, Costa Rica, una totalidad llena de contradicciones dialécticas; vale decir, en un movimiento complejo donde las contradicciones fundamentales se producen entre las formas de apropiación del espacio urbano por parte del capital transnacional en alianza con capitales locales, que controlan el sector comercial emergente en el casco urbano consolidado de la ciudad, en la apropiación por ellos mismos, de la periferia urbana, de los espacios naturales de montaña y de las zonas costeras del Cantón (figura 5), y los grandes espacios de barrios populares y marginales que han ido extendiendo la vieja mancha urbana.

\footnotetext{
${ }^{16}$ Según el último censo del Instituto Nacional de Estadísticas (INEC, 2011). El cantón de Liberia tenía 62.987 habitantes. En esa fecha el distrito central, es decir la ciudad de Liberia y su entorno concentraba el 85 por ciento de la población. El cantón cuenta con los distritos Cañas Dulces, 3.230 habs.; Mayorga 1.602 habs.; Nacascolo, 2.247 habs.; y Curubandé, 2.527 habs. Nuestros cálculos (no oficiales) se acercan en la actualidad a unos 63.000 habitantes en la ciudad de Liberia.
} 


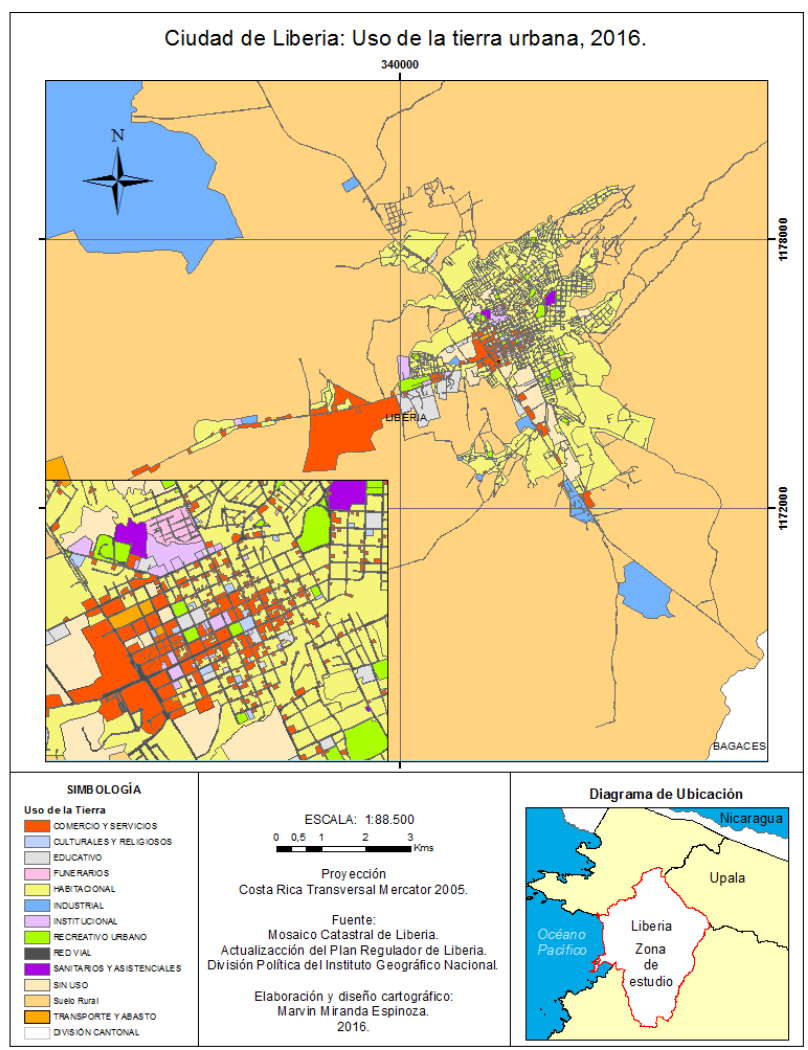

Figura 6. Ciudad de Liberia. El uso de la tierra es solo un elemento de la totalidad que la define.

Se consideran algunas de las variables que estructural y coyunturalmente, podrían explicar las formas del espacio que trasciende el antiguo núcleo urbano y la región de la que forma parte (ver figuras 4 y 5 ). Se estudia la dinámica de Liberia en sus procesos generales, desde sus manifestaciones cualitativas más evidentes, esto es, las formas concretas de fragmentación espacial: ¿Cómo se expresa visualmente esta fragmentación en el paisaje urbano, en la periferia urbana y en el rururbano? ¿Cuál debe ser la lectura crítica de los cambios en la morfología urbana? ¿De qué manera se manifiestan las contradicciones entre el ecosistema artificial de la urbe y la naturaleza transformada por nuevas actividades productivas y procesos culturales de diverso tipo? Y ¿̇de qué manera los procesos de producción y circulación de mercancías y de capital se articulan y modifican el paisaje, el territorio y la urbe? En fin, se describen y analizan las formas que asume la reproducción del capital en esa ciudad que tiende a globalizarse, a jugar un papel relevante como espacio intermedio y se abordan las contradicciones socio geográficas que ello genera: las desigualdades en el uso del medio físico-natural y cultural, la afectación de la calidad de vida de los habitantes $\mathrm{y}$, por tanto, la dificultad para lograr un desarrollo espacial equilibrado y socialmente justo a escala local. 
El objeto se construye a partir de comprender desde dónde estamos mirando y cómo definimos lo que obtenemos al interrogar al dato empírico, identificando el acontecer de los fenómenos, conceptos, indicadores y cómo estos se nos presentan en el espacio - tiempo, en el contexto particular donde se encuentra el potencial explicativo de lo estudiado, y el campo de posibilidades articuladas. Por ejemplo, identificando clases, fracciones y grupos en la formación social de la ciudad pequeña, del capitalismo "glocal, tal y como se resume en la figura 7.

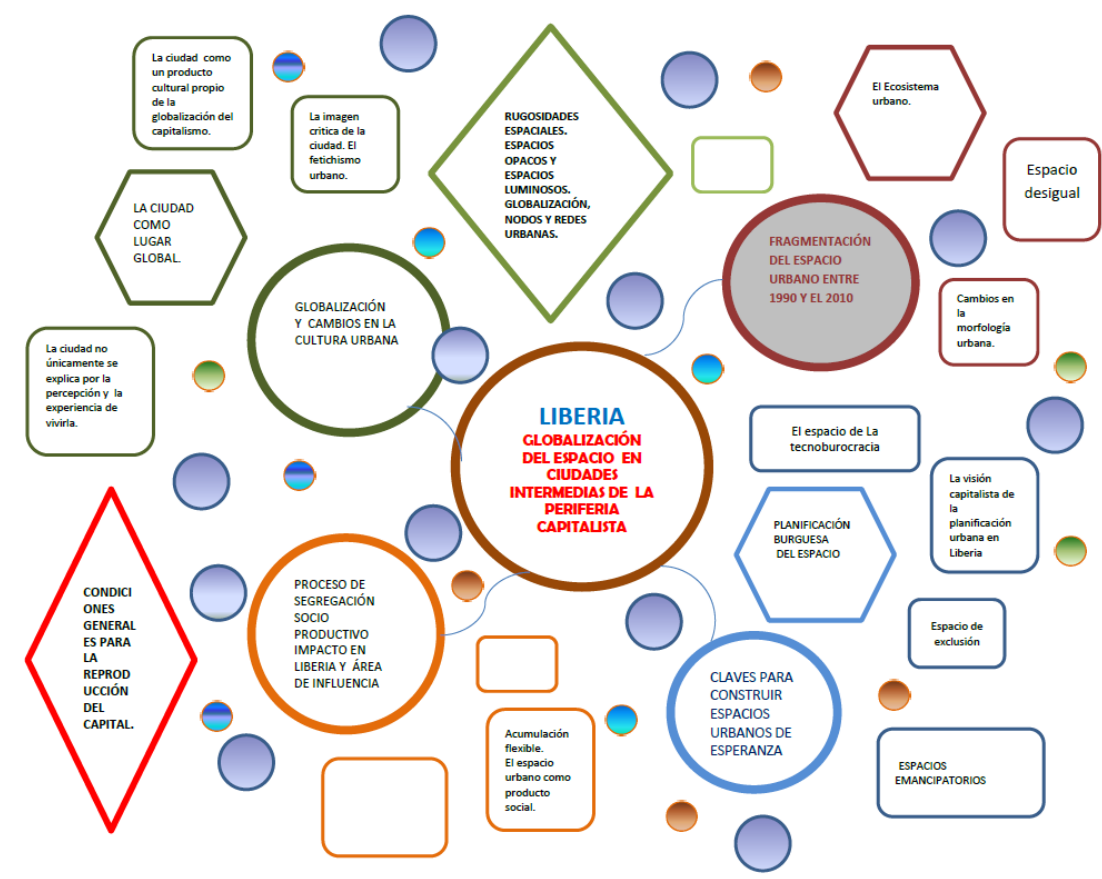

Figura 7. El acontecer de los fenómenos y su ritmo expresados en la articulación espacio-tiempo. El recorrido crítico implica mirar, como sujeto investigador, el conjunto de las circunstancias de la totalidad en estudio.

El espacio urbano siendo general es también particular. General en tanto, como ya se dijo, es un producto social, pero cuyo contenido es físico-natural y social. Incluye, pues, el componente de las relaciones sociales de producción, que responden a un modo de producción históricamente determinado. Pero es también particular porque las relaciones mencionadas se materializan en ciudades bajo un espacio-tiempo determinado con características específicas (de tales relaciones socioespaciales) propias de los procesos de acumulación en espacios periféricos, bajo nuevas formas de dependencia económica que son dictadas por la lógica del capitalismo en crisis (figura 7). 
El enfoque sobre el desarrollo geográfico desigual y su dinámica de fijación, movilización y reconfiguración espacio-temporal, servirá como marco de referencia para estudiar un caso particular que recrea los procesos históricos generales de la apropiación del territorio por parte del capital, pero desde lo singular. Es decir, el punto de partida es un objeto histórico espacial concreto: la ciudad de Liberia. Finalmente, se intenta observar las tendencias y, en ellas, las alternativas posibles en la construcción social de espacios urbanos de emancipación (ver la figura 1).

La totalidad en el objeto de estudio adquiere la forma de articulación entre áreas de relaciones sociales a través de conceptos ordenadores que llevan al indicador y al dato empírico (figura 1). Nótese como en esta investigación el objeto de estudio general, el espacio urbano en ciudades intermedias y la ciudad se entienden como una totalidad sistémica compleja que se construye (como objeto de conocimiento) bajo los principios de un método cuya esencia epistemológica comprende la idea de que el espacio urbano en general (y la ciudad en particular) es a la vez un producto tecnológico, es decir un artificio humano, y una construcción sociocultural que (envuelve» elementos materiales (la morfología urbana o el paisaje urbano, por ejemplo) que interactúan en forma dialéctica con el mundo de los elementos simbólicos propios del imaginario cotidiano popular y de la imaginación que ideológicamente construyen las sociedades clasistas y el mercado del consumismo. Estos dos últimos componentes ayudan a explicar los procesos de segmentación social, de desarrollo desigual de los espacios urbanos y de la voracidad con que actúan las leyes de la acumulación de capital en las urbes y su entorno inmediato (Ver figura 8).

\section{Desarrollo desigual, fragmentación del espacio y transformaciones culturales a partir de 1990 en Liberia y su área de influencia.}

En Liberia tienden a consolidarse en las últimas dos décadas los espacios urbanos destinados a las grandes superficies comerciales y las zonas monofucionales (como los espacios para alta tecnología y almacenamientos cercanos al aeropuerto internacional) y que constituyen formas de crecimiento urbano que tienden hacia la fragmentación física de la ciudad (figura 8). Conjuntamente, emergen los nuevos barrios marginales de la periferia urbana ecológicamente más degradada, o con una estética del paisaje natural no atractiva. Este proceso conduce también a la segregación urbana y a la aparición de grupos 
sociales pobres y excluidos de la ciudad (en Liberia son los trabajadores nicaragüenses y los pobres de la ciudad o provenientes de otras zonas del país que son movidos hacia los barrios marginales, en lo que se podría llamar la invisibilidad espacial del bono de la vivienda). De esta forma, Liberia, como otras ciudades de Centroamérica, pasa de ser una ciudad pequeña y compacta a ser una ciudad mucho más dual y difusa. El espacio en la ciudad es socioculturalmente apropiado de forma desigual por los distintos agentes que allí habitan y de manera fugaz por los transeúntes internacionales de la red global de los no lugares. ${ }^{17}$
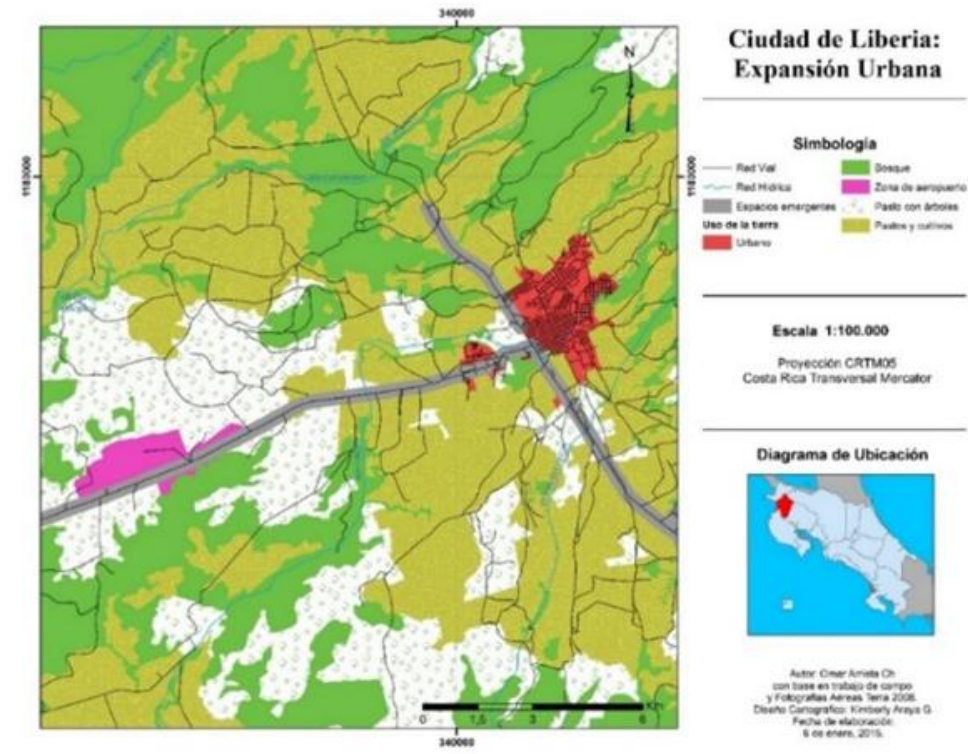

Figura 8. Difuminación incipiente de la pequeña ciudad intermedia en centroamérica.

Por otra parte, en los dos últimos períodos intercensales en Liberia se ha producido un crecimiento acelerado de la población y del espacio construido, aunado a una deficiente planificación urbana; procesos que han generado, entre otros cambios, nuevas contradicciones entre el destino del patrimonio público y la calidad de vida que ofrece la ciudad, así como una fuerte segmentación social en la periferia y en el área de influencia de una incipiente ciudad-región. El modelo de crecimiento urbano bajo la economía del mercado neoliberal ha promovido la acción pública en función de ampliar las condiciones generales para la reproducción ampliada del capital privado, la generación de excedentes y los procesos por desposesión, acción pública la mayoría de las veces por encima del bien común.

${ }^{17}$ En la idea de Augé, 1993 
Las grandes empresas nacionales y transnacionales tienden a definir, en los últimos años, el desarrollo de las ciudades apoyadas en la (iniciativa estatal» que actúa "en busca del bien común", desde la lógica de una economía local subordinada y dependiente del mercado global.

Estas políticas del Estado central a menudo hacen caso omiso de los procesos de planificación del territorio y de la gestión municipal. Algunas veces incluso la gestión se ejecuta con dificultades técnicas y de autonomía en los trámites para los proyectos cantonales; en fin, el ayuntamiento frecuentemente tiene poca posibilidad de definir o implementar políticas de desarrollo local y, por ello, tiende a resolver únicamente aquellos proyectos de infraestructura dictados desde el Estado central y sus aliados nacionales y transnacionales. Esto es muy claro cuando el gobierno local se ocupa prioritariamente de ejecutar proyectos que benefician a las empresas constructoras de grandes bienes inmuebles, o de zonas de almacenaje o de firmas que controlan el desarrollo de residenciales para sectores de alto poder adquisitivo.

Por otro lado, el movimiento social urbano es débil, tiende a fragmentarse o a enfrentar conflictos puntuales y coyunturales, lo cual impide la comprensión colectiva de que la ciudad es una construcción sociocultural histórica y que, por tanto, puede ser transformada con la participación ciudadana.

La vida cotidiana es un espacio social en el que se construye y reconstruye la realidad y, a pesar de su apariencia caótica, mantiene una estructura que la sostiene y que, justamente por su heterogeneidad, representa la complejidad de la realidad social que es desvelada en el espacio geográfico (en este caso urbano). El mercado privatiza cada vez más los espacios y su gestión, se pierde la capacidad de interactuar, de dialogar, de desarrollar proyectos comunes consensuados, lo cual debilita a la ciudad como espacio identitario y atenta contra la posibilidad de construir una ciudad a imagen y semejanza de sus pobladores.

La urbe aparece ante los sujetos como separada de ellos, ajena y alienante, y asumen que es inmutable. Esto ocurre en general para la ciudad construida bajo la lógica de la acumulación capitalista, de ahí que no existan ciudades totalmente democráticas ni emancipatorias bajo el reino de la acumulación privada 
de capital, ni bajo formas del Estado despótico, autoritario o en cualquier modelo de Estado en donde el poder se ejerza de manera asimétrica, donde se impongan formas imaginarias de un mundo propio de la utopía capitalista, lleno de grandes corporaciones tecnológicas y belicistas, de los hombres de empresa como un tal Bruce Wayne, junto al sórdido bajo mundo de los barrios de Gotham City.

\section{CONCLUSIÓN}

Si bien existen causas generales que explican la evolución reciente de las ciudades intermedias en un contexto de creciente globalización económica, también es posible encontrar condiciones locales y regionales que le otorgan rasgos específicos a esa evolución.

Pero ¿qué ocurre en aquellos espacios que siendo más o menos invisibilizados son atrapados por la red de la globalización? ¿Cuáles son las categorías que ayudan a explicar tal invisibilidad espacial? ¿De qué manera se explican los cambios ocurridos en núcleos de población como Cañas Dulces de Liberia, de no más de 3.000 habitantes, que se encuentran en la órbita de expansión del capital trasnacional? ¿De qué forma se vuelve visible?, ¿para quienes?, ¿por qué?, ¿cuál es su lado oscuro?, ¿para quién?, ¿por qué? ¿Qué opciones tienen los habitantes de los nuevos barrios que surgen en las pequeñas ciudades tomadas por la red global? ¿Cómo se construye un espacio de esperanza allí?

Problematizar el objeto de estudio en la ciudad de Liberia significó más que pensar los cambios socio culturales y morfológicos del casco urbano consolidado que obviamente han sido evidentes, pensar el cantón de Liberia como el nodo de una maraña rural y urbana compleja, comprender que los cambios han sido mucho más drásticos en el espacio difuso que se ha venido creando en la periferia y en los pequeños núcleos cabeceras de los distritos rurales del cantón, y en las transformaciones que sufre la línea de costa que tiende a ser la reproducción tropical centroamericana de las costas europeas que desde el siglo pasado fueron creadas para el turismo mundial.

Emancipar la ciudad es emancipación de la sociedad y se producirá solamente cuando los agentes sociales que la habitan, de manera consciente y consensuada, asuman su destino en la ciudad. La ruptura, a esta 
altura de la historia, no significa la desaparición del mercado total, pero sí, contribuir a su transformación desde lo local. Un mercado que siendo global se reconstruya en función de eliminar las grandes desigualdades que se producen en la distribución social y territorial de la riqueza, apostar por alianzas honestas entre las economías familiares y las empresas pequeñas y medianas de una economía para la vida más que para la acumulación de riqueza, desarrollar Estados que contribuyan a fortalecer los gobiernos locales y la autonomía en la gestión del desarrollo local con vocación social, promover gobernanzas democráticas que no se inclinen por el management privado ni por la Smart city sin más.

El método como reconstrucción de la realidad y enriquecimiento de la teoría es una herramienta que debe seguirse validando en los estudios del espacio geográfico. La mediación entre lo social y la naturaleza del espacio en las investigaciones dentro de la geografía se ve enriquecida con la apertura multidisciplinaria de este enfoque y contribuye a profundizar el conocimiento de la dimensión histórica del espacio urbano como construcción social a escala local, como aquí se ha esbozado

\section{REFERÊNCIAS}

Andrade, L. (2007). Del tema al objeto de investigación en la propuesta epistemológica de Hugo Zemelman. Cinta Moebio, (30), 262-282. Recuperado de http://www.facso.uchile.cl/publicaciones/moebio/30/andrade.html

Arrieta, O. (21 y 22 de junio, 2011). El derecho a una ciudad emancipatoria. VI Foro de Debates de los Pueblos y Culturas de las Américas, llevado a cabo en la Universidad Nacional, Heredia, Costa Rica.

Arrieta, O. (2012). Apuntes para un marco teórico metodológico del estudio de los espacios urbanos intermedios en países periféricos - en tiempos de la globalización neoliberal y desde un enfoque crítico-. Revista Geográfica de América Central, $2(49), 15-37$.

Arrieta, O. (2014). Ciudades intermedias y migraciones en Centroamérica. En Morales, A. (Comp.), Escenarios sociopolíticos de las migraciones en Costa Rica y Colombia (pp. 57-83). San José, C. R.: FLACSO.

Augé, M. (1993). Los (no lugares» espacios del anonimato. Una antropología de la sobremodernidad. Barcelona: Gedisa.

Barsky, A. (2005). El periurbano productivo, un espacio en constante transformación. Introducción al estado del debate, con referencias al caso de Buenos Aires. Scripta Nova. Revista Electrónica de Geografía y Ciencias Sociales, 9(194[36]).

Recuperado de http://www.ub.es/geocrit/sn/sn-194-36.htm>

Bolay, J. C. y Rabinovich, A. (2004). Ciudades intermedias: una nueva oportunidad para un desarrollo regional coherente en América Latina. En H. D. Alfonso (ed.), Globalización e intemediación urbana en América Latina (pp. 1-42). Santo Domingo, República Dominicana: FLACSO. Recuperado de http://nccrns.epfl.ch/public_pdf/ciudades_intermedias_bolay_rabinovich.pdf

Borja, J. y Castells, M. (2000). Local y global. La gestión de las ciudades en la era de la información (5. ㄹ edición). Madrid: Taurus. 
Cuervo, L. M. (2003). Pensar el territorio: los conceptos de ciudad-global y región en sus orígenes y evolución. Santiago, Chile: Naciones Unidas-ILPES-CEPAL. Recuperado de http://www.eumed.net/libros-gratis/2010d/788/

De la Garza, E. (2001). La epistemología crítica y el concepto de configuración: alternativas a la estructura y función estándar de la teoría. Recuperado de http://docencia.izt.uam.mx/egt/publicaciones/articulos/configuraciones.pdf

De la Garza, E. (2011). La metodología marxista y el configuracionismo latinoamericano. En E. de la Garza y G. Leyva (eds.), Tratado de metodología de las ciencias sociales: perspectivas actuales (pp. 229-255). México: Fondo de Cultura Económica. Recuperado de http://docencia.izt.uam.mx/egt/Cursos/MetodologiaMaestria/delaGarzaMetodologiapf

Dematteis, G. (1991). Sistemi locali nucleari e sistemi a rete. Un contributo geográfico all'interpretazione delle dinamiche urbane. En C. S. Bertuglia y A. La Bella (a cura di), I Sistemi Urbani. (pp.417-439) Milano: Franco Angeli.

Dematteis, G. (1998). Suburbanización y periurbanización. Ciudades anglosajonas y ciudades latinas. En F. Monclús (ed.), La ciudad dispersa. (pp.17-33) Barcelona: Centre de Cultura Contemporània.

Escolar, C. (1998). Epistemología del trabajo de campo en geografía: problemas en torno a la construcción de los datos. Biblio 3W. Revista Bibliográfica de Geografía y Ciencias Sociales, 96 (2), 6 pp.

Gómez, L. (2005). Problemas teóricos y metodológicos del estudio de la ciudad desde el modelo de urbe global. Aposta, (20), 1-14. Recuperado de http://www.apostadigital.com

Harvey, D. (1990). Los límites del capitalismo y la teoría marxista. México: Fondo de Cultura Económica.

Harvey, D. (23 de marzo, 1997). Las ciudades fragmentadas. Diario Página 12. Recuperado de http://www.pagina12.com.ar/buscador/index.php

Harvey, D. (2000). Spaces of Hope. Berkeley, CA: University of California Press.

Harvey, D. (2004). La condición de la posmodernidad. Investigación sobre los orígenes del cambio cultural. Buenos Aires: Amorrortu.

Harvey, D. (30 de agosto, 2006a). Una geografía urbana posible. $2^{0}$ Encuentro El Pensamiento Urbano. Centro Cultural San Martín. Buenos Aires. Recuperado de http://www.georedweb.com.ar/

Harvey, D. (2006b). Space of Global Capitalism: Towards a Theory of Uneven Geographical Development. LondonNew York: Verso.

Harvey, D. (2009b) ¿Estamos realmente ante el fin del neoliberalismo? La crisis y la consolidación del poder de las clases dominantes. Recuperado de http://es.scribd.com/doc/16303289/Harvey-David-La-crisis-actual-y laconsolidacion-del-poderde-las-clases-dominantes-2009

Harvey, D. (mayo-agosto, 2010a). Organización para la transición anticapitalista. Argumentos, 23(63), 35-58. Recuperado ehttp://www.scielo.org.mx/scielo.php?script=sci_arttext\&pid=S0187-57952010000200003

Harvey, D. (2010b). The Enigma of Capital and the Crisis of Capitalism. New York, USA: Oxford University Press.

Jameson, F. (1991). Ensayos sobre el posmodernismo. Buenos Aires: Ediciones Imago Mundi.

Jessop, B. (2006). Spatial Fixes, Temporal Fixes and Spatio-Temporal Fixes. En N. Castree y D. Gregory (eds.), David Harvey. A Critical Reader (pp. 142-165). Malden- Oxford Carlton: Blackwell.

Lois, C. (2015). El mapa como metáfora o la espacialización del pensamiento. Terra Brasilis (Nova Série) [En línea], 6 | 2015, Publicado el 17 diciembre 2015, consultado el 30 abril 2019. URL: http:// journals.openedition.org/terrabrasilis/1553; DOI:10.4000/terrabrasilis.1553

Peláez, J. E. (2015). La cartografía como texto y herramienta de modelización del Mundo. En: Astrolabio, Nueva Época, (15), pp. 151-173. Recuperada de: https://revistas.unc.edu.ar/index.php/astrolabio/article/view/12423

Pineda, I. (2011). La problematización como registro de posibilidades para la investigación educativa. Multidisciplina, (10), 115-125. Recuperado de www.acatlan.unam.mx/multidisciplina/file.../119/multi-2011-09-08.pdf

Pulido, N. (2006a). El espacio urbano latinoamericano y la globalización. Emergencia de “ciudades intermedias» y nuevos cambios en Venezuela. En A. I. Geraiges, M. Arroyo y M. L. Silveira (eds.), América Latina: cidade, campo e turismo, 
(pp.149-171) San Pablo: CLACSO. Recuperado de http://bibliotecavirtual.clacso.org.ar/ar/libros/edicion/lemos/09pulido.pdf

Reynoso, C. (2007). Edgar Morin y la complejidad: elementos para una crítica. Universidad de Buenos Aires-Grupo Antropocaos, Argentina. Recuperado de http://txtantropologia.files.wordpress.com/2007/10/carlos-reynoso-edgar-morin-yacomplejidad-2007.pdf

Smith, N. (2009). 'Toxic Capitalism'. New Political Economy, 14(3), 407-412. Recuperado de http://www.tandfonline.com/doi/abs/10.1080/13563460903087623\#.VI3ZFyuG-

Soja, E. W. (1989). Postmodern Geographies: The Reassertion of Space in Critical Social Theory. New York: Verso.

Soja, E. W. (2000). Posmetrópolis: critical studies of cities and regions. Los Ángeles, C.A.: Blackwell Publishing.

Zemelman, H. (1990). Horizontes de la razón. Barcelona: Anthropos.

Zemelman, H. (2011a). Horizontes de la razón III. El orden del movimiento. Barcelona: Anthropos.

Zemelman, H. (2011b). Conocimiento y sujetos sociales. Contribución al estudio del presente. [Con la colaboración de Alicia Martínez]Vicepresidencia del Estado Plurinacional de Bolivia. La Paz, Bolivia. Recuperado de http://www.vicepresidencia.gob.bo/IMG/pdf/zemelman-2.pdf 